\title{
MACROCELERIDADE ELEITORAL E A IRRECORRIBILIDADE DE DECISÕES INTERLOCUTÓRIAS: UMA NECESSÁRIA REVISÃO
}

\author{
Electoral Macro-Celerity and Impossibility of Interlocutory Appeal: a necessary review
}

Anna Paula Oliveira Mendes

D Marina Almeida Morais

Resumo: O presente trabalho busca apresentar uma leitura crítica à irrecorribilidade das decisões interlocutórias no direito processual eleitoral. Por meio de revisão bibliográfica e estudo de caso, evidencia-se que a proibição ao manejo do agravo de instrumento para impugnar imediatamente determinadas decisões incidentais, a pretexto de promover o princípio da celeridade, pode subvertê-lo, o que vai de encontro ao ideal de macroceleridade eleitoral. A conclusão do trabalho apresenta uma proposta de solução para a problemática encontrada, apontando a necessidade de uma reforma eleitoral para que o agravo de instrumento passe a ser aceito em determinadas hipóteses.

Palavras-chave: Celeridade eleitoral. Agravo de Instrumento. Reforma Eleitoral. Irrecorribilidade. Decisões interlocutórias.

\begin{abstract}
This work presents a critical analysis of the impossibility of interlocutory appeal in electoral procedural law. The study carries out a bibliographic and jurisprudential review to demonstrate that the impossibility of interlocutory appeal to challenge certain incidental decisions under the pretext of promoting the principle of celerity can subvert the same principle, which goes against the ideal of electoral macro-celerity. The case study of AIJE 224-63.2016.6.09.0083/GO, presented in the article, illustrates how the prohibition of the interlocutory appeal can hinder the effectiveness of the judicial provision and extend the duration of the procedure. The conclusion presents a proposal to address this issue, suggesting an electoral reform so that the interlocutory appeal becomes accepted in specific hypotheses.
\end{abstract}

Keywords: Electoral celerity. Interlocutory appeal. Electoral reform. Impossibility to appeal. Interlocutory decisions.

Artigo recebido em 27 abr. 2021 e aprovado em 13 jul. 2021

Editor responsável: Luiz Magno Pinto Bastos Junior

DOI: https://doi.org/10.53323/resenhaeleitoral.v25i1.133 


\section{Introdução}

A celeridade foi erguida, na Constituição da República de 1988, ao status de direito fundamental. É assegurado a todos a razoável duração do processo e meios que garantam a celeridade da sua tramitação (art. 5o, LXXVIII). No Direito Processual Eleitoral, em razão de características próprias da disciplina, como a temporalidade dos mandatos eletivos e o curto lapso de tempo que dura o período eleitoral, a celeridade ganhou uma posição de ainda mais destaque, permeando inúmeros institutos da matéria. Mas seria tal princípio um fim em si mesmo?

O presente trabalho busca imprimir uma leitura crítica à irrecorribilidade das decisões interlocutórias que hoje existe no Direito Processual Eleitoral, para, ao final, apresentar uma proposta de solução à questão.

A norma proibitiva de recursos em face das decisões interlocutórias, que se tratou originariamente de uma construção jurisprudencial do Tribunal Superior Eleitoral, visa promover a celeridade que deve imperar nos feitos que tramitam perante a Justiça Eleitoral. No entanto, com base no conceito de macroceleridade, idealizado por Roberta Maia Greta, será demonstrado que a proibição indiscriminada ao agravo de instrumento pode ter, em realidade, um efeito danoso à duração razoável do processo.

Esta afronta à macroceleridade eleitoral é observada quando não é possível à parte se insurgir imediatamente contra uma nulidade processual, a qual só vem a ser declarada quando do julgamento do recurso em face da sentença, importando na necessidade do retorno dos autos à origem. Com isso, atos processuais já praticados precisam ser refeitos, demandando um maior lapso temporal até uma decisão definitiva do mérito da questão, o que compromete a efetividade do provimento jurisdicional.

Para testar a hipótese levantada, far-se-á um estudo de caso a respeito da AIJE 224-63.2016.6.09.0083/GO, que tramitou por quase quatro anos, sendo que, por quase dois anos (26/12/2017 a 02/10/2019), os andamentos referiram-se à matéria afeita ao indeferimento de prova, não recorrível de plano.

Por fim, como forma de apresentar uma proposta de solução à problemática identificada, propor-se-á a admissão do agravo de instrumento, na seara processual eleitoral, em previsão similar à do Código de Pro- 
cesso Civil, de modo que este passasse a ser aceito em face de decisões interlocutórias que versarem sobre: I - tutelas provisórias; II - mérito do processo; III - exclusão ou admissão de litisconsorte; IV - produção de provas; $\mathrm{V}$ - outros casos expressamente referidos em lei. Acredita-se que a previsão em incisos, ainda que com caráter taxativo mitigado, conforme entendimento do STJ, se prestaria a evitar a propositura indiscriminada do recurso, mantendo a celeridade esperada nos feitos eleitorais.

\section{O princípio da celeridade no direito processual eleitoral}

O Direito Eleitoral é o ramo do direito público que regula o direito ao voto, a organização das eleições e garante a legitimidade do seu resultado. O sistema de governo republicano adotado no Brasil, por sua vez, pressupõe a temporalidade dos mandatos eletivos. Deste modo, tendo em vista a temporalidade dos mandatos e a brevidade do período eleitoral propriamente dito, isto é, o período compreendido entre as convenções partidárias e a diplomação dos eleitos, pode-se dizer que garantir a legitimidade das eleições é uma corrida contra o tempo. Não por outra razão, a celeridade é um dos princípios basilares do Direito Eleitoral. Rodrigo López Zilio sintetiza tal ideia ao afirmar que:

O princípio da celeridade é um dos mais relevantes da esfera eleitoral. Decorre fundamentalmente da temporalidade dos mandatos eletivos e do rígido calendário eleitoral. Como o processo eleitoral é delineado por fases preestabelecidas e sucessivas (v.g. convenção, registro, propaganda, etc.), com dia certo para início e término, os processos que correm perante a Justiça Eleitoral devem primar por um andamento célere (ZILIO, 2020, p. 46).

A celeridade foi alçada, na Constituição de 1988, ao status de direito fundamental. Consta do art. 5, LXXVIII, que "a todos, no âmbito judicial e administrativo, são assegurados a razoável duração do processo e os meios que garantam a celeridade de sua tramitação".

O ideal da celeridade é positivado em diversas normas da dogmática eleitoral e, especialmente, do direito processual eleitoral. Decorre diretamente da celeridade, por exemplo, o exíguo prazo para a interposição 
dos recursos eleitorais, cuja regra geral é o prazo de 3 (três) dias ${ }^{1}$ mas, em hipóteses específicas, chega ser de apenas 24 (vinte e quatro) horas ${ }^{2}$.

O contorno rígido que o princípio da celeridade recebe no Direito Processual Eleitoral, bem como inúmeras outras particularidades dessa disciplina, a colocam como um ramo do direito autônomo ao Direito Processual Civil. Assim, as normas do direito processual civil apenas devem ser aplicadas, na seara eleitoral, em caráter supletivo e subsidiário, e desde que haja compatibilidade sistêmica.

Diante do advento do Código de Processo Civil de 2015, o Tribunal Superior Eleitoral editou a Resolução n⿳0 23.478 de 2016, na qual disciplinou diretrizes gerais para a aplicação do NCPC (Lei no $13.106 / 2015)$ no âmbito da Justiça Eleitoral. Nesta normativa, é trazido de modo expresso a especialidade do Direito Processual Eleitoral e a supletividade e subsidiariedade do Direito Processual Civil em relação aos feitos que tramitam na Justiça Eleitoral ${ }^{3}$.

$\mathrm{Na}$ afirmação da especialidade da matéria, e também demonstrando a posição de destaque da celeridade no Direito Processual Eleitoral, a Resolução n⿳0 23.478/2016 estabelece que não se aplicam aos feitos eleitorais a contagem de prazos em dias úteis (art. $7^{\circ}$ ), bem como que os prazos processuais durante o período definido no calendário eleitoral não se suspendem nos finais de semana e feriados e, fora desse período, serão contados nos termos do art. 224 do NCPC (art. 7오 $\int 1^{\circ}$ e e $\int 2^{\circ}$ ). A resolução ainda determina que, durante o período previsto no calendário eleitoral, não se aplica a regra contida no art. 205, $\int 3^{\circ}$, do NCPC, que determina que os despachos, decisões interlocutórias, sentenças e acórdãos sejam publicados no Diário de Justiça Eletrônico, admitindo-se a publicação em cartório, sessão ou a utilização de edital eletrônico (art. 13).

\footnotetext{
${ }^{1}$ Art. 258, Lei no 4.737/1965. Sempre que a lei não fixar prazo especial, o recurso deverá ser interposto em três dias da publicação do ato, resolução ou despacho.

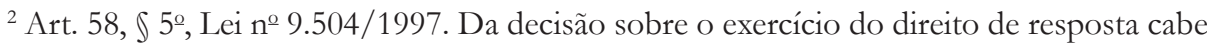
recurso às instâncias superiores, em vinte e quatro horas da data de sua publicação em cartório ou sessão, assegurado ao recorrido oferecer contrarrazões em igual prazo, a contar da sua notificação.

${ }^{3}$ Art. 2을 Resolução nº 23.478/2016. Em razão da especialidade da matéria, as ações, os procedimentos e os recursos eleitorais permanecem regidos pelas normas específicas previstas na legislação eleitoral e nas instruções do Tribunal Superior Eleitoral.
} 
Percebe-se, portanto, que é intrínseco à especialidade do Direito Processual Eleitoral a posição de destaque que a celeridade recebe na matéria. Nessa toada, igualmente positivou-se, no art. 19 da Resolução no 23.748/2016 ${ }^{4}$ a irrecorribilidade das decisões interlocutórias no Direito Eleitoral, conforme será explanado no tópico a seguir.

\section{Irrecorribilidade de decisões interlocutórias e a macro- celeridade eleitoral}

As decisões interlocutórias, de acordo com o critério residual adotado pelo art. 203, \ 2\% , do NCPC, são entendidas como todo o pronunciamento judicial que não seja a sentença (NEVES, 2017). Caso a decisão não coloque fim à fase de conhecimento ou extinga a execução, será considerada uma decisão interlocutória. Muito embora a decisão interlocutória possa ter como conteúdo uma questão de mérito, como ocorre nos casos de julgamento antecipado parcial da lide, esta trata, comumente, de questões incidentais, como sobre questões probatórias (deferimento ou indeferimento de prova pericial, oitiva de testemunhas, etc.).

No Direito Processual Eleitoral, por meio de uma construção jurisprudencial, passou-se a entender que as decisões interlocutórias são irrecorríveis, buscando-se, com isso, privilegiar unicamente a celeridade que deve nortear a condução desses feitos.

Cita-se, abaixo, o posicionamento adotado pelo Ministro Eduardo Ribeiro na ocasião do julgamento do Agravo de Instrumento n $1.718 / \mathrm{MS}$ (1999), o qual sagrou-se vencedor no egrégio Tribunal Superior Eleitoral, e norteou inúmeros outros julgados que vieram posteriormente:

Parecem-me que, não só no caso em exame, como no processo eleitoral em geral, necessariamente concentrado, tendo em vista a indispensável celeridade, há de entender-se que não há possibilidade de recorrer, em separado, das decisões interlocutórias. Não ficarão preclusas e serão reexaminadas quando do recurso interposto contra aquela que coloque fim ao processo. Agravo de instrumento será cabível contra decisão que não admita recurso ${ }^{5}$.

\footnotetext{
${ }^{4}$ Art. 19. As decisões interlocutórias ou sem caráter definitivo proferidas nos feitos eleitorais são irrecorríveis de imediato por não estarem sujeitas à preclusão, ficando os eventuais inconformismos para posterior manifestação em recurso contra a decisão definitiva de mérito. ${ }^{5}$ TSE. Agravo de Instrumento no 1718 - Mato Grosso do Sul, Relator Ministro Eduardo Ribeiro, publicado no DJe em 11/06/1999.
} 
Não se pode dizer que o entendimento acima adotado foi imune às críticas. Há posicionamento do Ministro Fernando Neves, em 2002 (Mandado de Segurança 210), no sentido de admitir a interposição de agravo de instrumento para o combate às decisões interlocutórias:

Particularmente, penso que, em certas hipóteses, deve ser admitido o recurso de agravo para atacar essas decisões e, embora os precedentes da Corte se restrinjam à modalidade do agravo retido, entendo possível também o uso do agravo de instrumento, na linha de entendimento que defendi no julgamento do Recurso em Mandado de Segurança $\mathrm{n}^{\circ} 187$, de 04/10/2001, de que fui relator, em que admiti a possibilidade de se impugnar imediatamente as decisões interlocutórias proferidas em investigação judicial.

Nesse ponto, entendo que não merece reparos a decisão regional que assentou ser cabível o agravo de instrumento contra decisão proferida pelo juiz eleitoral em ação de impugnação de mandato eletivo, ponderando ainda que, em primeira instância, o procedimento a ser seguido é o rito ordinário previsto no $\mathrm{CPC}^{6}$.

Apesar da divergência acima citada, o entendimento que se sagrou majoritário no Tribunal Superior Eleitoral foi aquele que reconhece a irrecorribilidade das decisões interlocutórias pela via do agravo de instrumento. Em 2016, com o advento da Resolução do TSE 23.748/2016, este ganhou status de norma, positivado no artigo 19:

Art. 19. As decisões interlocutórias ou sem caráter definitivo proferidas nos feitos eleitorais são irrecorríveis de imediato por não estarem sujeitas à preclusão, ficando os eventuais inconformismos para posterior manifestação em recurso contra a decisão definitiva de mérito.

Não há dúvidas que a irrecorribilidade das decisões interlocutórias na seara eleitoral é uma forma de privilegiar a celeridade dos feitos submetidos à Justiça Eleitoral. No entanto, se buscará defender, no presente trabalho, que o impedimento absoluto ao manejo do referido recurso, em que pese privilegie uma microceleridade - isto é, a celeridade daquele momento processual específico -, deixa de prestigiar a macroceleridade. Explica-se: a impossibilidade do combate imediato de decisões interlocutórias pode

\footnotetext{
${ }^{6}$ TSE. Recurso em Mandado de Segurança no 210 - Piauí, Relator Ministro Fernando Neves, publicado no DJe em 02/08/2002.
} 
levar à nulidade de todo o processado, importando na determinação, pela instância superior, de uma nova instrução processual e julgamento para a correção do vício. É o que acontece, por exemplo, quando o magistrado de piso indefere a produção de uma prova suplementar e, por ausência de recurso imediato, apenas em sede de recurso eleitoral se reconhece o cerceamento de defesa no feito.

Nas palavras de Roberta Maia Gresta, a ideia de macroceleridade eleitoral pode ser definida da seguinte forma:

Ante a particularidade de o procedimento eleitoral (eleições) ser sujeito a temporalidade certa, o controle jurisdicional sobre ele incidente deve considerar, sob a ótica da celeridade, que o retorno a etapas procedimentais anteriores pode acarretar extremo prejuízo à efetividade do processo. Por isso, pequenas dilações, no curso da ação eleitoral, justificam-se sempre que necessárias para o saneamento efetivo do processo. Nesse sentido, é possível falar de um princípio da macroceleridade do processo eleitoral, que favorece a racionalidade do procedimento ao acolher técnicas, como o agravo de instrumento, a produção antecipada de provas e a contagem de prazo em dias úteis, que se mostram aptas a assegurar que o trâmite das ações siga consistentemente adiante (GRESTA, 2021, online).

Com isso, será demonstrado que uma proposta legislativa que admita o agravo de instrumento, no direito processual eleitoral, para o combate de determinadas decisões interlocutórias, não vai de encontro ao lugar de destaque que a celeridade tem nesse ramo do direito, mas, ao contrário, busca resguardá-la, privilegiando a macroceleridade do processo eleitoral.

\section{Estudo de caso: ação de investigação judicial eleitoral (AIJE) 224-63.2016.6.09.0083/GO}

O presente estudo pretende identificar em que medida a irrecorribilidade das decisões interlocutórias pode apresentar um efeito reverso àquele proposto no momento de sua instituição. Em outras palavras, perquire-se a possibilidade de que, em busca da celeridade processual, acabe-se por desprestigiar a macroceleridade, eivando o feito de nulidades processuais que culminem no retorno dos autos à origem e ocasionem uma maior duração para a prática repetida de atos. Para fundamentar as hipóteses levantadas, elegeu-se o estudo do caso dos autos 224-63.2016/GO. 
O processo em questão foi escolhido por preencher os requisitos de: i) existência de decisão interlocutória que tratasse de produção de prova ou ingresso de partes; ii) transcurso regular do feito seguido de decisão da instância superior determinando o retorno dos autos à origem; e iii) ocorrência de trâmite prolongado do processo em razão do reconhecimento do desacerto/ nulidade da decisão interlocutória. Assim, a despeito da escolha, espera-se que as conclusões obtidas pelo presente estudo se apliquem a quaisquer outros casos concretos que apresentem também essas três ocorrências concomitantes.

\subsection{Do método}

Com efeito, qualquer escolha metodológica pressupõe uma renúncia a todas as outras. É sabido que as críticas ao estudo de caso são frequentes, atribuindo ao método a probabilidade de análises intuitivas e impressionistas, que pouco transcendem a meros relatos e lhe atribuindo a pecha de se afastar do que se espera da produção de conhecimento científico.

Todavia, há que se sopesar os benefícios de cada método: no presente caso, o estudo de um objeto delimitado possibilita identificar uma realidade empírica do fenômeno, que não se conseguiria descrever por levantamento amostral e avaliação exclusivamente quantitativa.

De maneira mais específica, conforme informações da Seção de Jurisprudência e Acórdão do TRE-GO, nos feitos referentes às eleições de 2016, 45 processos retornaram à origem em razão do reconhecimento de alguma nulidade pelo Tribunal. Isso não equivale a dizer que todos eles poderiam ser solucionados com a possibilidade de interposição de agravo: muitos deles, por exemplo, retornaram pela ausência de citação válida.

Nesse sentido, o problema de pesquisa não pode ser satisfeito por meio de uma análise quantitativa, notadamente porque a frequência de casos não é o ponto principal do estudo. Não é preciso que muitos processos tenham sido afetados pela reiteração de atos processuais: se um caso demonstra que um processo tramitou por tempo suficiente para que sua utilidade perecesse, já se tem indício de que o sistema está se tornando incompatível com a proposta inicial.

Assim, não se pretende construir uma falácia ecológica, tomando o caso concreto individualmente como se regra fosse para o conjunto de processos. O que se busca é demonstrar uma falha do sistema e propor uma solução que se considera adequada ao problema enfrentado. Para esse desiderato, portanto, compreende-se a metodologia de estudo de caso como satisfatória. 


\subsection{O caso da AIJE 224-63.2016}

A ação foi proposta em 01/10/2016, em razão da suposta prática de abuso de poder político, consistente na utilização de serviços de servidor público estadual em campanha eleitoral de candidatos durante o seu horário normal de expediente. A inicial defendia que o fato do servidor público em questão ter participado de caminhadas, carreatas, visitas e do horário eleitoral em programas de emissora de rádio comunitária, em prol dos candidatos, teve o condão de macular o princípio da probidade administrativa, influindo de forma ilícita nas eleições e, consequentemente, desequilibrando o pleito.

Recebida a inicial e apresentadas as defesas, o processo foi remetido ao Ministério Público que, em 16/11/2016, requereu a designação de audiência para oitiva de testemunhas arroladas pelas partes, conforme preconiza o art. 22, V, da Lei Complementar nº 64/1990. Em 19/10/2017, sobreveio despacho indeferindo a oitiva de testemunhas, com o seguinte teor:

Observa-se que, dos fatos narrados pela parte autora, apenas a questão relacionada às datas em que o senhor Francisco de Assis Peixoto supostamente estava realizando campanha eleitoral, em São Simão/ GO, para Gabriel e para Gilmar, poderiam ensejar a necessidade de oitiva de testemunhas. Ocorre que esse fato foi confessado por Francisco de Assis Peixoto. Logo, não depende de prova, segundo dicção legal do artigo 374, inciso II, do Código de Processo Civil.

Noutro diapasão, constata-se que as questões aduzidas pelos investigados são unicamente de direito, portanto, despiciendo a oitiva de testemunha.

Por consequência, prescindível é a designação de audiência. Assim, conforme assevera o artigo 355, inciso I, do Código de Processo Civil, a desnecessidade de produção de outras provas enseja o julgamento antecipado do mérito.

Ante a impossibilidade de recurso imediato, o processo seguiu para prolação de Sentença que, em 01/11/2017, julgou improcedente o pedido, sob o argumento de que a parte autora não se desincumbiu de provar o direito alegado. Nessa quadra, apenas no Recurso Eleitoral o autor pode se insurgir contra o indeferimento da produção de provas - argumento acolhido pelo Relator. 
Em 09/04/2018, foi publicada decisão monocrática em que se consignou que seria "manifesta a violação ao direito de produção de provas pela parte autora, porquanto controversa a questão relativa às datas nos quais o recorrido Francisco teria feito campanha eleitoral em São Simão”. Sob esse entender, o Relator cassou a sentença e determinou a remessa dos autos à origem para a produção das provas requeridas pelo recorrente.

Com efeito, da decisão monocrática é cabível Agravo Interno, manejado pelos recorridos. Negado provimento ao Agravo, foram ainda opostos Embargos de Declaração e interposto Recurso Especial, também negados. Assim, apenas em 02/10/2019 os autos retornaram à origem para processamento.

A audiência para oitiva de testemunhas foi realizada em 12/12/2019, visando a esclarecer se o servidor público investigado estaria comparecendo a atos de campanha em dias úteis e em horário de expediente no período eleitoral de 2016.

Ouvidas as testemunhas, a nova sentença foi publicada em 28/08/2020, julgando improcedente o pedido, sob o argumento de que não haveria prova cabal de que o servidor estaria no município pedindo votos durante o seu expediente de trabalho e "nem mesmo na audiência de instrução, realizada em 19 de dezembro de 2019, tal fato ficou provado". Não havendo a superveniência de recurso, o processo transitou em julgado na data de 10/09/2020.

Independentemente do mérito da questão, em que se pudesse questionar se a presença de um único servidor estadual em atos de campanha municipal seria suficiente a desequilibrar o pleito e deslegitimar o resultado das eleições, avalia-se aqui o quesito temporal, em que o processo tramitou por quase quatro anos, sendo que por quase dois anos (26/12/2017 a 02/10/2019) os andamentos referiram-se a matéria afeita ao indeferimento de prova, não recorrível de plano.

No caso em apreço, é de se ressaltar, os candidatos não lograram ser eleitos no pleito municipal de 2016. A despeito disso, fosse o caso de terem sido diplomados, e se entendendo ao final pela prática de ilícito efetivamente danoso à democracia, ter-se-ia o mandato exercido indevidamente em sua inteireza, em descompasso a um dos preceito mais caros do ordenamento eleitoral, qual seja, o da legitimidade das eleições. 
O caso reforça, portanto, que o princípio da celeridade não justifica, por si só, a irrecorribilidade das decisões interlocutórias, notadamente quando na prática é possível que a impossibilidade de recurso imediato atrase sobremaneira o deslinde processual.

\section{Previsão do agravo de instrumento na reforma eleitoral: uma proposta}

Resta firmado que o princípio da celeridade rege toda a logística das normas eleitorais - e é salutar que assim o seja, dada a brevidade do período de atos que antecedem a eleição dos representantes do povo, e dos prejuízos irreparáveis que a demora na prolação de decisões pode ocasionar à legitimidade do sistema. Por outro lado, a preocupação exacerbada em imprimir aos processos eleitorais a maior celeridade possível acaba, não raro, em retardar os feitos, atentando contra a já mencionada ideia de macroceleridade, conceito cunhado por Roberta Maia Gresta.

Um desses problemas reside na impossibilidade de insurgência imediata às decisões interlocutórias, com o consequente deslinde da demanda até apreciação pela instância superior. Nesses casos, a decretação de nulidade dos atos praticados após a prolação da decisão interlocutória, com a determinação de retorno dos autos à origem, tem o condão de retardar o feito em tempo superior ao destinado à análise de um possível recurso.

A irrecorribilidade de decisões interlocutórias soa adequada a um sistema mais simples e menos complexo, que não demande maior instrução probatória. Esse não é o caso das ações de cassação, que são, por essência, contramajoritárias e podem culminar na invalidação da vontade soberana expressa nas urnas.

Também não é demais lembrar que, em um momento em que a Reforma Eleitoral avança, com vias a redigir um Código de Processo, estampa-se o reconhecimento de que o Direito Processual Eleitoral não é um sistema simplório, que demanda atenta sistematização.

Neste sentido, e dada a discussão firmada no tópico de estudo de caso, é de se propor que, dada a insuficiência de argumentos para manter a irrecorribilidade das decisões interlocutórias, o sistema passe a oferecer instrumento para insurgências, isto é, que se preveja o agravo de instrumento para esses casos. 
A proposição, como solução ao problema de pesquisa, é uma previsão similar à do Código de Processo Civil, prevendo a possibilidade de agravo de instrumento contra decisões interlocutórias que versarem sobre: I - tutelas provisórias; II - mérito do processo; III - exclusão ou admissão de litisconsorte; IV - produção de provas; V - outros casos expressamente referidos em lei.

Bem se sabe que, no julgamento do Recurso Especial nº 1.704.250/ MT, o Superior Tribunal de Justiça reconheceu a possibilidade de impugnação de decisões interlocutórias não previstas nos incisos do art. 1.015 do CPC, defendendo uma taxatividade mitigada e permitindo a interpretação extensiva, analógica ou exemplificativa para casos que, embora não incluídos no rol, apresentem relevante urgência ${ }^{7}$.

A mesma lógica poderia ser aplicada aos feitos eleitorais. A necessidade de elencar um rol se justifica pelo desígnio de evitar a propositura indiscriminada do recurso, que, com efeito, poderia atentar contra a celeridade esperada. Todavia, considerar-se-á mitigada a taxatividade, para que, demonstrada a urgência e a perda da utilidade do provimento em caso de aguardar o Recurso Eleitoral, seja possível manejar o agravo. Entende-se como redação plausível, portanto, a seguinte:

Art. xx. Caberá agravo de instrumento contra as decisões interlocutórias que versarem sobre:

I - tutelas provisórias;

II - mérito do processo;

III - exclusão ou admissão de litisconsorte;

IV - produção de provas;

$\mathrm{V}$ - outros casos expressamente referidos em lei.

Art. xx. Recebido o agravo de instrumento no tribunal e distribuído imediatamente, o relator, no prazo de 3 (três) dias:

I - poderá atribuir efeito suspensivo ao recurso ou deferir, em antecipação de tutela, total ou parcialmente, a pretensão recursal, comunicando ao juiz sua decisão;

II - ordenará a intimação do agravado via Diário da Justiça Eletrônico, para que responda no prazo de 3 (três) dias, facultando-lhe juntar

\footnotetext{
7 "O rol do art. 1.015 do CPC é de taxatividade mitigada, por isso admite a interposição de agravo de instrumento quando verificada a urgência decorrente da inutilidade do julgamento da questão no recurso de apelação.” (Recurso Especial nº 1.704.520 - MT (2017/0271924-6). Relatora: Ministra Nancy Andrighi, julgamento em 05 de dezembro de 2018).
} 
a documentação que entender necessária ao julgamento do recurso; III - determinará a intimação do Ministério Público, preferencialmente por meio eletrônico, quando for o caso de sua intervenção, para que se manifeste no prazo de 3 (três) dias.

Art. xx. O relator solicitará dia para julgamento em prazo não superior a 15 (quinze) dias da intimação do agravado.

A previsão do primeiro inciso se respalda na lógica de que, se o ordenamento prevê tutelas provisórias, não parece adequado que não haja forma de insurgência contra elas. Quanto aos demais, se prestam exatamente a evitar que os feitos transcorram eivados de nulidades que só possam ser corrigidas em sede de recurso em face da sentença. Tal como no Código de Processo Civil, o recurso não seria dotado de efeito suspensivo, que poderá ser atribuído pelo relator, caso assim entenda, reforçando a inexistência de prejuízo ao deslinde célere do feito originário.

Entende-se assim que, além de não conflitar com a celeridade esperada nos feitos eleitorais, a possibilidade de interposição do agravo de instrumento contribui para a garantia do devido processo legal e para o reparo imediato de eventuais nulidades, evitando prejuízos às partes e ao processo como um todo.

\section{Considerações finais}

O dever de prestígio à celeridade nos feitos eleitorais decorre de algumas premissas. A primeira delas é a de que o próprio período eleitoral assim compreendido aquele entre as convenções partidárias e a diplomação dos eleitos - tem brevíssima duração, sendo de, atualmente, pouco menos de cinco meses. Nesse contexto, a exiguidade dos prazos se justifica no desiderato de que as controvérsias porventura existentes sejam solucionadas imediatamente, garantindo a normalidade das eleições. As ações que tramitam após o fim do período eleitoral, por sua vez, gozam de igual urgência, dado que os mandatos têm duração determinada e os feitos que busquem desconstituí-los devem ser decididos com brevidade, a fim de garantir a legitimidade dos ocupantes dos cargos eletivos.

Essa particularidade dos feitos eleitorais conduziu ao entendimento de que a possibilidade de recurso imediato retiraria dos processos sua necessária celeridade, de modo que atualmente essas decisões não comportam recurso. 
A prática, todavia, fez surgir o problema objeto desse estudo: não raro, a impossibilidade de recurso imediato culmina em alguma nulidade processual, pronunciada pelo órgão recursal, que determina o retorno a etapas procedimentais anteriores, ocasionando uma demora ainda maior para a conclusão da demanda.

A hipótese levantada, portanto, foi de que é possível justificar pequenas dilações no curso da ação eleitoral, em nome da preservação da macroceleridade do processo eleitoral, isto é, de um princípio maior que permita ao processo tramitar sem vícios que demandem a repetição de atos.

O estudo de caso realizado confirmou a existência de hipóteses em que a possibilidade de recurso imediato poderia ter evitado a repetição de atos e a demora exacerbada do feito. Embora tenha sido eleito um único caso, repisa-se que a metodologia quantitativa não teria satisfeita a inquietação a que se refere a pesquisa. Isso porque a frequência de casos não é o ponto principal do problema, mas os indícios de que, se um processo tramitou por tempo suficiente para que sua utilidade perecesse, em razão da irrecorribilidade imediata, já se tem a hipótese de que o sistema tem se tornado incompatível com a proposta inicial de celeridade.

Nesse sentido, a proposta é a previsão do agravo de instrumento como insurgência imediata a decisões interlocutórias, em casos de evidente urgência e cuja pretensão perderia a utilidade caso fosse aguardado o manejo do Recurso Eleitoral.

A proposta é que o recurso não tenha efeito suspensivo automático, de modo que o feito originário possa continuar a tramitar - salvo nos casos em que o relator atenda a pedido de suspensão. Encontra-se assim um meio termo apto a sopesar os prós e contras de uma exigência intrínseca de celeridade nos feitos eleitorais.

Nesse contexto, visando ao alcance do ideal de macroceleridade eleitoral, prestigia-se a efetividade da prestação jurisdicional pela Justiça Eleitoral e, em última instância, normalidade e legitimidade das eleições. 


\section{Referências}

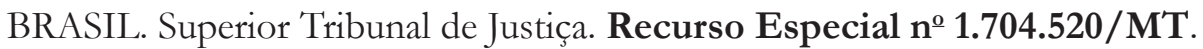
Relatora: Ministra Nancy Andrighi, julgamento em 05/12/2018, publicação no DJe de 19/12/2018.

GOIÁS. Tribunal Regional Eleitoral de Goiás. Ação de Investigação Judicial Eleitoral no ${ }^{\circ}$ 224-63.2016.6.09.0083.

GRESTA, Roberta Maia. Macroceleridade eleitoral. Grupo de Trabalho da Reforma Eleitoral - Câmara dos Deputados e Academia Brasileira de Direito Eleitoral e Político, 2021.

ZILIO, Rodrigo López. Direito Eleitoral. 7. ed. Salvador: JusPodvim, 2020.

Anna Paula Oliveira Mendes - Mestre em Direito da Cidade pela Universidade do Estado do Rio de Janeiro (UERJ). Professora de Direito Eleitoral da Universidade Iguaçu (UNIG). Servidora do quadro efetivo do TRE/RJ, atualmente lotada na Coordenadoria de Assuntos Jurídicos da Corregedoria Regional Eleitoral. E-mail: annapaula.om@gmail.com. ORCID: https://orcid.org/0000-0001-9228-8969.

Marina Almeida Morais - Advogada. Mestre em Ciência Política pela Universidade Federal de Goiás (UFG), Especialista em Direito Eleitoral e em Direito Público pela Universidade Cândido Mendes (UCAM), membro da Academia Brasileira de Direito Eleitoral e Político (ABRADEP), coordenadora da Comissão de Estudos Eleitorais da OAB/GO (2019/2021). E-mail: adv.marinamorais@gmail.com. ORCID: https://orcid.org/00000002-3530-0340. 
